\title{
Genomic insights into the adaptation to parasitism in nematode - trapping fungi and transcriptomics during infection of Caenorhabditis briggsae and plant-parasitic nematodes*
}

\author{
DHARMENDRA KUMAR \\ Department of Plant Pathology, Narendra Deva University of Agriculture \& Technology, Kumarganj, \\ Faizabad 224 229, Uttar Pradesh, India
}

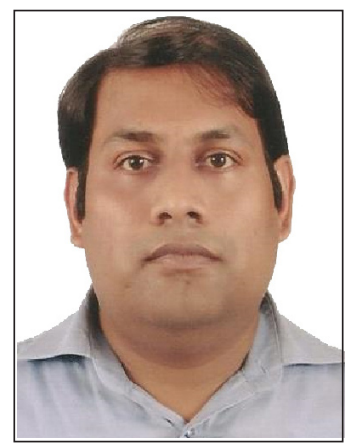

Received: 11 November 2016/ Accepted: 20 February 2017/ Published online: 23 March 2017 (C) Indian Phytopathological Society 2017

\begin{abstract}
Nematode-trapping fungi are a group of soil living microorganisms that form special adhesive and mechanical trapping structures to capture and kill the nematodes. Nematode- trapping fungi belong to a family Orbiliaceae of Phylum Ascomycota. Many plant parasitic nematodes species are destructive plant pathogens which resulted in an interest to use nematode-trapping fungi as bio control agents of plant parasitic nematodes. Comparative genomics and transcriptomics were used to gain insights in to the adaptation to parasitism in nematode-trapping fungi. Sequenced the genome of Monacrosporium haptotylum and compared with the genome of the adhesive net forming species Arthrobotrys oligospora. The genome assembly contains $\mathbf{4 0 . 4}$ million base pairs and 10959 genes. Two genomic mechanisms are likely to be involved in the evolution of parasitism in nematode- trapping fungi. First, gene duplications leading to formation of novel genes and expansion of gene families resulting in a large number of species - specific genes. Many of these genes were highly expressed and upregulated during infection of Caenorhabditis briggsae. Second, the differential gene expression of orthrologs between the two fungi during infection, suggest that the differential gene expression has been an important mechanisms for evolution of parasitism in nematode-trapping fungi. The transcriptome expressed by Arthrobotrys oligospora, Monacrosporium cionopagum and Arthrobotrys dactyloides during infection of root-knot nematode Meloidogyne hapla and sugar beet cyst nematode Heterodera schachtii were studied. Comparative transcriptome analysis during infection process including trapping, penetration and digestion of Meloidogyne hapla and Heterodera schachtii by nematode-trapping fungi showed that the divergence in gene expression pattern associated with fungal species was significantly larger than that related to the host nematode species. Genes that were highly expressed in all nematode-trapping fungi encoded endopeptidases, such as peptisase_S8, peptidase_M3 and aspartic proteases; cell-surface proteins containing the carbohydrate-binding domain WSC; stress response proteins; membrane transporters; transcription factors; and cell singling genes containing the Ras domain. Transcripts containing the Ricin-B lectin and Atg8 domain were also highly expressed in all nematode- trapping fungi. Differentially expressed transcripts among the fungal species encoded various lectins, such as the fungal fruit-body lectin and the D-mannose binding lectin; transcription factors; cell-signaling components; proteins containing a WSC domain; and proteins containing a DUF3129 domain. Interestingly, DUF 3129 was highly expressed in $M$. cionopagum but not expressed at all in $A$. dactyloides. Differentially expressed transcripts during infection of different host nematodes, including peptidases, WSC domain proteins, tyrosinases, and small secreted proteins with unknown function.
\end{abstract}

Keywords: Caenorhabditis briggsae, Heterodera schachtii, Meloidogyne hapla, nematode - trapping fungi, Transcriptomics

The term nematode-trapping fungi (NTFs) is used to describe a fascinating group of nematophagous fungi that kill and consume the free living as well as plant and animal parasitic nematodes after trapping them by their specialized adhesive and non-adhesive hyphal traps. NTFs are also known to capture other microscopic animals such as rhizopods, copepods and rotifers (Rubner, 1996). Other groups of nematophagous fungi

${ }^{*}$ M.K. Patel Memorial Young Scientist Award lecture delivered in Mid-Eastern Zonal Meeting of Indian Phytopathological Society and National Symposium at Banaras Hindu University, Varanasi, Uttar Pradesh on 18.12.2015

Email: dkumar_nduat@yahoo.in are endoparasites, egg and female parasites of root-knot and cyst nematodes, and toxin producing fungi (Jansson et al., 1997; Jansson and Lopez-Llorca, 2001). Since the discovery of the nematode-capturing ability of Arthrobotrys oligospora by Zopf in 1888, NTFs have attracted the attention of mycologist across the world because of the spectacular method of capturing and infection of free living, plant and animal parasitic nematodes. Because of their ability to capture and parasitize the nematodes, they can be used as potential bio control agent of plant and animal parasitic nematodes. NTFs grow as facultative saprophytes in soil depending on their competitive saprophytic ability. These fungi switch 
over from saprophytic to predacious / parasitic phase by forming trapping devices in which nematodes are captured mechanically or by adhesion. Trapped nematodes become paralyzed (immobilized), when fungus starts to penetrate the nematode cuticle (Dijksterhuis et al., 1994). The morphology of the traps of NTF differs depending on the species. Traps are basically adhesive knobs, adhesive network, adhesive branches, constricting rings and non-constricting rings. Rubner (1996) subdivided the trapping devices into seven type i.e. simple adhesive branches, unstalked adhesive knobs, stalked adhesive knobs, non-constricting rings, constricting rings, two dimensional networks and three dimensional networks. Traps of NTFs usually developed on hyphae in response to chemicals secreted by nematodes, peptides and spontaneously.

\section{Trapping structures and induction of traps}

Trapping devices are the most important infectious structures of NTFs to trap, kill and consume the nematode content to survive particularly in soil having an instance microbial competition for nutrients. NTFs usually forms traps on hyphae either spontaneously or be induced in response to signals from the environment, including peptides and other chemicals secreted by the host nematode. The ratio of carbon/nitrogen also influences the trap formation in soil environment (Dijksterhuis et al., 1994). Types of the traps produced by nematode trapping fungi are given below:

\section{Adhesive network}

One of the most common traps of nematode-trapping fungi is three-dimensional adhesive network. Formation of adhesive network start with the outgrowth of lateral branches from growing hyphae, which subsequently curve and anastomose to form complex three dimensional network. Ex. Arthrobotrys oligospora, Arthrobotrys conoides, Arthrobotrys eudermata, Arthrobotrys musiformis (Fig. 1).

\section{Adhesive hyphal branches}

Adhesive hyphal branches consist of one to several elongated cells produces on the hyphae densely side by side (Fig. 1). When the adhesive branches tend to anostomose, they are called two dimensional networks. The ability of the hyphal branches to form bridges is use as a main criterion to separate M.cionopagum with simple adhesive branches (Fig. 1) and M. gephyropaghum with anastomosed branches (two dimensional networks, Fig. 1). Ex. Monacrosporium cionopagum, M. gephyropagum.

\section{Adhesive sessile and stalked knobs}

Adhesive knobs are the globose or subglobose cells that is either produced on stalked attached with hypha (stalked adhesive knobs, Fig. 1) or produced sessile knob on the hyphae (unstalked adhesive knobs, Fig. 1). Ex. Monacrosporium haptotylum, Monacrosporium phymatopagum.

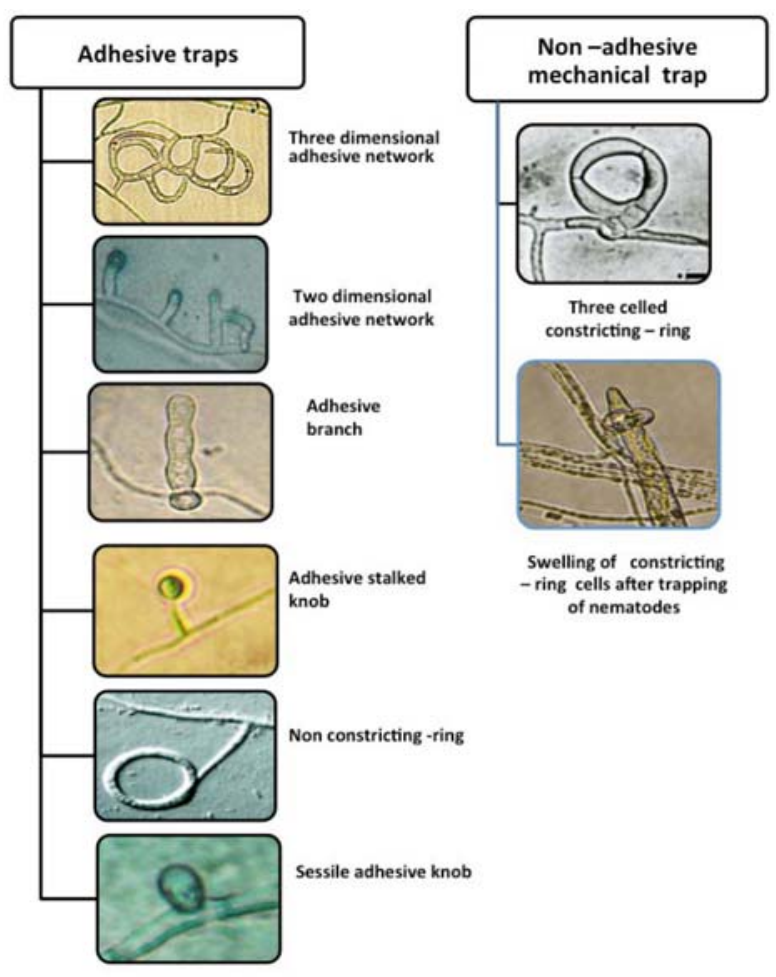

Fig. 1. Trapping organs of nematode - trapping fungi

\section{Non-constricting rings}

Non-constricting rings are erect lateral branches from vegetative hypha thicken and curve to form a generally three celled rings that then fused to the supporting stalk (Fig. 1).

\section{Constricting rings}

The constricting-rings are three celled and most sophisticated trapping device captures nematodes in a different way. When nematode enters into constricting rings, the three celled rings swells rapidly inwards and tightly captured the prey within 1-2 seconds (Fig. 1). Ex. Arthrobotrys dactyloides, Dactylaria brochopaga.

\section{Habitat}

Nematode-trapping fungi are soil inhabitants and found in almost all types of soil but they are most predominant in the soil having high organic matter. The most common nematode trapping fungi found in almost all types of soil are $A$. eudermata and $A$. oligospora. Only few species of NTF have been reported from aquatic and especially marine environment. Nematode-trapping fungi can grow as saprophyte in soil and as parasite using nematodes as nutrients source. The nematode- trapping fungi develop hyphal structures such as adhesive nets, adhesive knobs, adhesive branches, constricting rings and non- constricting rings to capture nematodes.

\section{The infection process}

Nematode-trapping fungi captures and parasitize nematodes in a sequence of events including adhesion 
to the nematode surface or trapping, followed by penetration, digestion and growth into the nematode body (Dijksterhuis et al., 1994). Species of nematode- tapping fungi forming adhesive traps capture nematodes by extracellular polymers that accumulate at the site of infection whereas constricting rings captures the nematodes by rapid swelling of ring cells (Fig. 2,3). Following trapping by adhesion or mechanical, nematode-trapping fungi form a penetration tube which pierces the nematode cuticle (Dijksterhuis et al., 1994). In Arthrobotrys oligospora, the penetration process is a combination of the activity of hydrolytic enzymes, such as proteases, and a mechanical pressure of penetrating fungus. The cuticle of nematode consists mainly of proteins including collagen (Cox et al., 1981) and various proteases have been isolated from nematophagous fungi that can hydrolyse proteins of the nematode cuticle. The penetration tube swells to form a large infection bulb in the nematode body. From the mature infection bulb, trophic hyphae develops and allow the fungus to grow and utilize the nutrients of the nematode for further growth.
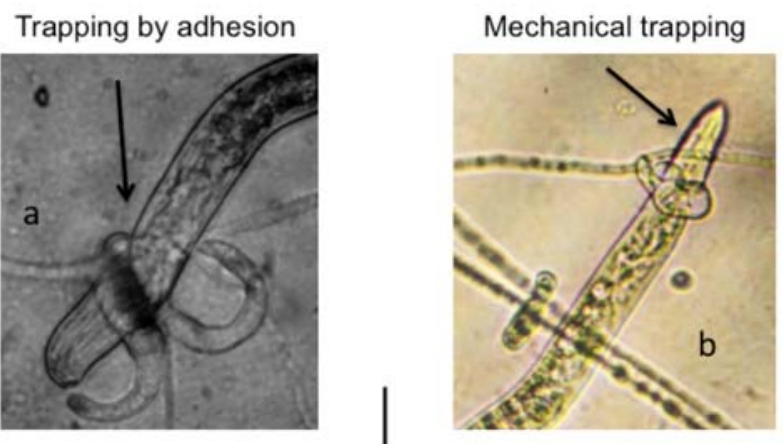

Penetration of cuticle of nematode

Formation of infection bulb

Paralysis of nematodes

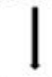

Growth of fungal hyphae inside nematodes and degradation of nematode body by fungal enzymes.

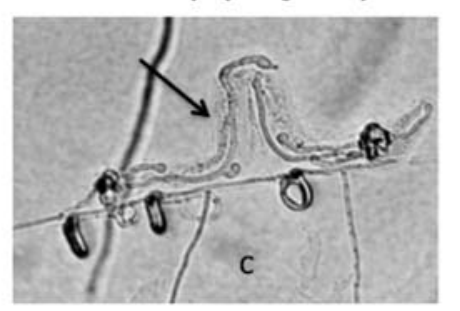

Fig. 2. Steps of nematode infection by nematode - trapping fungi. (a) Capturing of free-living nematode by adhesive trap of nematode trapping fungus $(\times 350)$, (b) Capturing of Meloidogyne hapla by constricting ring of $A$. dactyloides (×350), (c) Growth of fungal hyphae of $A$. dactyloides in the nematode by after consuming the content of nematode body $(\times 150)$
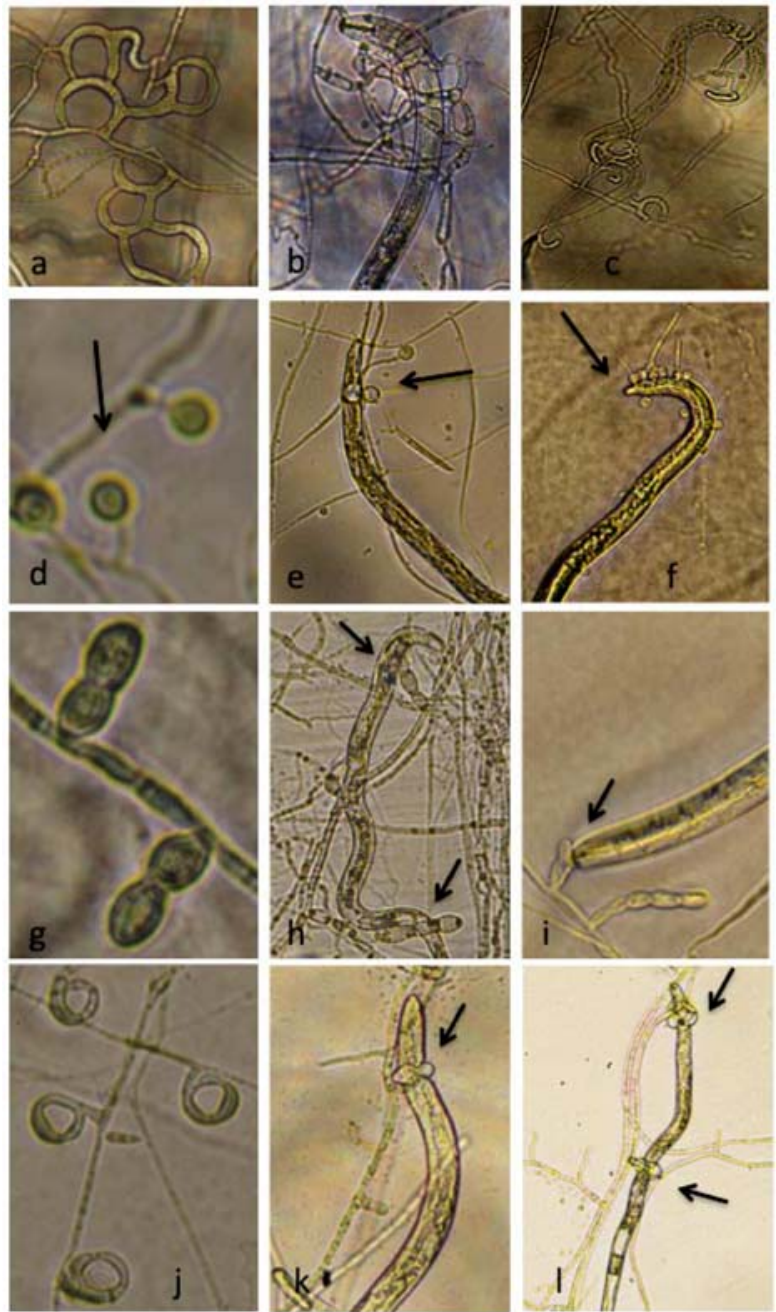

Fig. 3. (a) Adhesive network of A. oligospora (× 200), (b) Trapping of Heterodera schachtii by adhesive network of A.oligospora (× 150), (c) Trapping of Panagrellus redivivus by adhesive network of A.oligospora $(\times 100)$, (d) Adhesive stalked knob of $M$. haptotylum (×125), (e) Trapping of $M$. hapla by adhesive knob of $M$. haptotylum $(\times 100),(f)$ Trapping and penetration of $M$. hapla by adhesive knob of $M$. haptotylum (125), (g) Adhesive branch of $M$. cionopagum $(\times 450)$, (h) Trapping of $M$. hapla by adhesive branch of $M$. cionopagum (× 160), (i) Trapping of $H$. schachtii by adhesive branch of $M$. cionopagum $(\times 225)$, (j) Constricting rings of $A$. dactyloides ( $\times 200)$, (k) Trapping of $H$. schachtii by constricting ring of $A$. dactyloides $(\times 170)$, (I) Trapping of $M$. hapla by constricting ring of $A$. dactyloides $(\times 170)$

\section{Growth and parasitic ability of nematode-trapping fungi in fungistatic environment of soil}

Disease suppressing potential of any nematode- trapping fungi in nematode infested soil depends on the successful germination of conidia and formation of specialized traps to capture the nematodes. Several workers reported that presence of fungistatic factor in soil are inhibitory to the growth of fungi. Therefore, the ability of nematode trapping fungi to overcome the soil fungistasis is of paramount importance for the bio control potential of these fungi. Some species of NTFs also form traps directly on the conidium or small germlings of conidia (conidial trap) in response to soil fungistasis, animal dung 

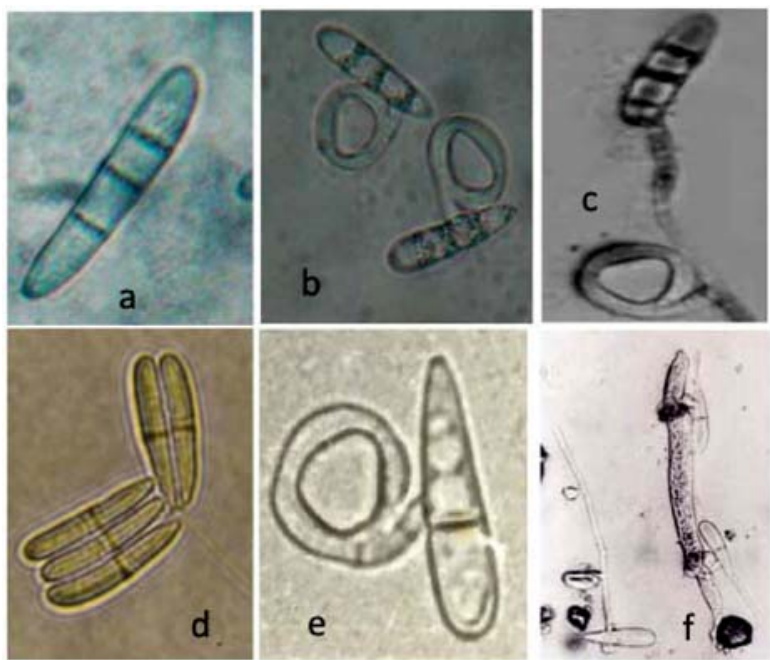

Fig. 4. (a) Conidia of Dactylaria brochopaga $(\times 550)$, (b) Conidial trap of $D$. brochopaga $(\times 300)$, (c) Trap on the germ tube of $D$. brochopaga $(\times 250)$, (d) Conidia of $A$. dactyloides (x $570)$, (e) Conidial trap of $A$. dactyloides ( $\times 650$ ), (f) Trapping and killing of soil nematodes by conidial trap of $A$. dactyloides $(\times 170)$

and nematodes. These conidial traps are depends on the capturing and killing of the nematodes for subsequent growth and survival. Dackman and Nordbring-Hertz (1992) called conidial traps as survival structure to overcome fungistatis. Arthtobortys dactyloides, Monacrosporium gephyrophagum (Parsmark and Nordbring-Hetrz, 1997) and Dactylaria brochopaga frequently form conidial traps on water agar disk in vicinity to soil and trap the nematodes (Fig. 3). Arthrobotrys oligospora also form frequent conidial traps in close contact to cow dung (Dackman and Nordbring-Hertz, 1992). The ability of $D$. brochopaga and $A$. dactyloides to form the conidial traps in the vicinity of soil and trapping of soil nematodes (Fig. 4) indicates that this fungus has enormous potential to reduce the nematodes in soil (Singh, 2010; Kumar et al., 2015).

\section{Bio-control potential of nematode trapping fungi against root knot nematodes}

Some species of nematode-trapping fungi are potential biocontrol agents of plant parasitic nematodes. Application of mass culture of Arthrobotrys dactyloides and Dactyalria brochopaga grown on barley substrates by method developed by Kumar et al. (2005) was found effective against the root-knot disease of tomato and rice. The number of root knots, females, egg masses and second stage juveniles of root knot nematodes were found to reduce by the application of colony forming units of A.datyloides and D.brochopaga in tomato and rice (Kumar and Singh, 2006; Singh et al., 2007).

\section{Genome sequence and general genomic features of Monacrosporium hayotyluum}

To know the genomic mechanism responsible for adaptation of parasitism in nematode trapping fungi,
Table 1. General features of genome of $M$. haptotylum and $A$. oligospora

\begin{tabular}{lcc}
\hline Features & M. haptotylum & A. oligospora \\
\hline Size (MB) & 40.4 & 40.07 \\
Protein coding genes & 10,599 & 11,497 \\
Genes encoding secreted proteins & 1666 & 1568 \\
Protein with P fam domain & 7455 & 7555 \\
Virulence associated proteins & 1161 & 1132 \\
\hline
\end{tabular}

genome of the adhesive knob forming fungus Monoacrosporium haptotylum was sequenced to 28 fold coverage using 454 pyrosequencing and compared with the available genome sequence of Arthrobotrys oligospora (Yang et al., 2011). The genome size of $M$. haptotylum was estimated to $40.4 \mathrm{Mb}$ and protein-coding genes to 10,959 which are more or less similar to the numbers for $A$. oligospora (Table 1). Transposable elements (TEs) were identified in $M$. haptotylum and $A$. oligospora. Tandem duplications of the genes in families were identified in $M$. haptotylum. In total, 147 duplicated pairs consisting of 272 genes were identified as being located in tandem positions. The proportion of genes encoding secreted proteins in $M$. haptotylum was estimated to be 1,666 (Table 1). Identified 1,161 proteins in M. haptotylum and 1,132 proteins in A. oligospora that are similar to proteins in the Pathogen-host interaction protein database (PHI-base database), particularly from plant pathogens. PHI-base contains a collection of experimentally verified pathogenicity, virulence and effector genes from fungi, oomycetes and bacteria (Winnenburg et al., 2006).

\section{Role of gene family expansions in adaptation of parasitism in nematode-trapping fungi}

Gene families are groups of genes descended from a common ancestor that retain similar sequences and often similar functions (Dayhoff, 1976). Expansion of lineagespecific genes as a result of the differential duplication and deletion of genomic regions has been shown to provide selective advantages and contribute to adaptation in a variety of organisms, including fungi (Lespinet et al., 2002). The gene family expansions and contractions in the genomes of $M$. haptotylum and $A$. oligospora by analyzing the gene family evolution by comparing the genome of 16 fungi were studied. The change in size of 848 gene families of $M$. haptotylum of which $326(38.4 \%)$ gene families were expanded and $522(61.6 \%)$ contracted. Out of 806 gene families that changed in A. oligospora, 362 (44.9\%) were expanded and $444(55.1 \%)$ were contracted. The lowest proportion of gene families expansion among the ascomyceteous fungi was found in Neurospora crassa branch (9\%) and the highest in Metarhizium anisopliae (52.6\%). The expansion of gene families of the nematode-trapping fungi was similar to Magnaporthae oryzae (38.0\%) inciting sheath blight of rice and higher than Metarhizium acridum (26.9\%, Table 2). The nematode-trapping fungi shared more gene families being expanded between plant pathogenic fungi as compared to insect - or animal 
Table 2. Expended gene families in nematode trapping fungi and some Ascomycota

\begin{tabular}{lc}
\hline Neurospora crassa & $9 \%$ \\
Metarhizium anisopliae & $52.6 \%$ \\
Magnaporthe oryzae & $38.0 \%$ \\
Nematode-trapping fungi & $38.4 \%$ \\
Metarhizium acridium & $26.9 \%$ \\
\hline
\end{tabular}

- pathogenic fungi. 28 expanded gene families were found shared between nematode-trapping fungi and plant pathogens. The nematode-trapping fungi and insect pathogens shared fewer numbers of expanded gene families and the nematode and animal pathogens the least ( 9 and 2 families, respectively).

A comparative analysis of gene families and the expanded Pfam domain families revealed strong similarities. The expansion of gene families in $M$. haptotylum and $A$. oligospora was found matched with all 25 expanded Pfam domains. This indicates that the expanded Pfam domain families are important for the evolution of the two nematode-trapping species (Meerupati et al., 2013).

\section{Identification of core, lineage- and species-specific genes of M. haptotylum and A. oligospora}

Comparative genomic analysis of $M$. haptotylum and $A$. oligospora showed that the these two nematode-trapping fungi contained a large number of lineage-specific and species-specific genes. We found that the around $62 \%$ genes of $M$. haptotylum and $A$. oligospora were shared by other fungi; around $20 \%$ of the genes were shared between $M$. haptotylum and $A$. oligospora and up to $16 \%$ of the genes were unique for each fungal genome. The lineage-specific and species-specific groups were enriched for genes involved in transcription, cytoskeleton, cell wall/membrane/envelope biogenesis, secretion and signal transduction whereas the core regions contained homologs of genes involved in metabolism and energy production (Meerupati et al., 2013).

\section{Gene expression in $M$. haptotylum during infection of Caenorhabditis briggsae}

Gene expression related with nematophagous phase of $M$. haptotylum was studied by inoculation of L1 larvae of the nematode $C$. briggsae to the adhesive knobs (traps) of $M$. haptotylum. After 4 hours of infection, approximately $98 \%$ C. briggsae were trapped and killed. A significant enrichment of species-specific genes was found in the cohort of the ten-fold upregulated genes. Of the $10 \%$ highly expressed genes during infection of $C$. briggsae by $M$. haptotylum (1,069 genes), 117 were more than ten-fold upregulated. In total, 38 of these 117 infectionregulated genes were specific for the $M$. haptotylum lineage, 15 were unique for the $M$. haptotylum and $A$. oligospora lineage and 64 common to other fungi (core genes). These 117 infection related genes were enriched in species - specific genes encoding secreted proteins, small secreted proteins (SSPs) and genes identified to belongs to expanded gene families. In total, 36 of the 117 regulated genes $(31 \%)$ were from expanded Pfam domain families. The expanded Pfam domain families were primarily encoded by the core set of genes and they contained the DUF3129, WSC, tyrosinase, mucin and peptidase S8 families (Meerupati et al., 2013). Twenty-eight of the highly infection-regulated genes showed sequence similarities to proteins in the PHI-base, including the members of the DUF3129 Pfam domain family that encode the gas 1 proteins of the rice blast fungus Magnaporthe oryzae (Xue et al., 2002), an extracellular cutinase (PBC1) from a plant pathogen ( $\mathrm{Li}$ et al., 2003), a tetraspanin homolog from Colletotrichum lindemuthianum (Veneault-Fourrey, et al., 2006), and RBT4 from Candida albicans (Braun et al., 2000).

\section{Comparative transcriptomics}

The transcriptome of $M$. haptotylum and $A$. oligospora expressed during the infection of $C$. briggsae was compared to know the difference between these two fungi. Analysis of the sequences of the $10 \%$ most highly expressed genes in $M$. haptotylum (which included 1,069 genes) showed that these were slightly enriched with secreted proteins. Among them, 200 proteins (19\%) were predicted to be secreted proteins of which 84 were SSPs. In the transcriptome of $A$. oligospora, seventy-two secreted proteins were identified among the $10 \%$ most highly expressed genes (in total 1,145 genes) of which 10 were SSPs. Genes from expanded Pfam domain families were highly expressed in both fungi, including the subtilisin (peptidase S8), tyrosinase, CFEM, DUF3129 (gas1), WSC and GLEYA families. Detailed analysis of the expression of genes shared between the two nematode-trapping fungi was performed. In total, $2,599(32 \%)$ of the 8,121 ortholog pairs showed significant difference in fold change (q-value $<0.01$ ) between the two fungi. The orthologs displaying the largest differences in expression values, that is, those that were more than 10-fold up- or down-regulated in the pairwise comparison between $M$. haptotylum and $A$. oligospora, were enriched with genes encoding secreted proteins, including many lineage-specific genes and SSPs. Several expanded Pfam domain families were also enriched among the differentially expressed genes (Meerupati et al., 2013).

\section{Mechanisms of Adaptation of parasitism in nematode- trapping fungi}

Two genomic mechanisms are likely to have been of major importance during the evolution of parasitism in nematode-trapping fungi:

- Formation of novel genes through gene duplication leading to the expansion of gene families resulting in a large number of species-specific genes. Many of species-specific genes were highly expressed and upredualted during infection of nematodes.

- Differential expression of orthologous genes between $M$. haptotylum and $A$. oligospora during 
early stage of infection suggests that differential gene expression has been an important mechanism for the evolution of parasitism in nematode trapping fungi.

\section{Commonly expressed genes of nematode trapping fungi during infection of plant parasitic nematodes}

Transcriptome of Arthrobotrys oligospora (adhesive net forming fungus, Monacrosporium cionopagum (adhesive branch forming fungus) and Arthrobotrys dactyloides (Constricting ring forming fungus) were studied during infection of Meloigodyne hapla (root-knot nematode) and Heterodera schachtii (sugar beet cyst nematode). The commonly expressed genes of $A$. dactyloides, $A$. oligospora and $M$. cionopagum during infection of Meloidogyn hapla and Heterodera schachtii were subtilisin (peptidase_S8), aspartyl proteases, CFEM (a fungal specific cysteine-rich domain that is found in some proteins with proposed roles in fungal pathogenesis) (Kulkarni et al., 2003), and the carbohydrate-binding WSC domain (Andersson et al., 2013; 2014; Meerupati et al., 2013), Pfam domain RicinB_lectin_2 (ribosomeinactivating proteins), proteins involved in fungal stress response, cell signaling, organization of the cytoskeleton, vesicular transport and membrane transport, as well as several families of calcium-binding proteins and transcription factors. Domains of enzymes and proteins involved in the carbon, energy and amino-acid metabolism and protein synthesis were also highly expressed by nematode trapping fungi. Furthermore, transcripts containing the Atg8 domain (an essential protein in autophagic pathway) were highly expressed in A. dactyloides, A. oligospora and M. cionopagum. A. oligospora has 52 genes containing the peptidase_S8 domain (Meerupati et al., 2013). However, only one transcript containing the peptidase_S8 domain was identified among the highly expressed transcripts in each library of $A$. oligospora infecting $M$. hapla and $A$. oligospora infecting $H$. schachtii (Andersson et al., 2014). The other cDNA libraries contained also only one transcript with the peptidase_S8 domain among the top 500 expressed genes. Stress proteins were highly expressed in all nematode trapping fungi. They included heat-shock proteins and chaperones such as DnaJ, HSP70 and HSP90; gluthatione S-transferases; and antioxidant enzymes such as thioredoxin and catalase.

\section{Interspecific variation in gene expression}

Differentially expressed transcripts among the fungal species encoded peptidases (peptidase_M1 and peptidase_M24), lectins (FB_lectin, B_lectin, RicinB_lectin_2), tyrosinase, transcription factors, cellsignaling components, Atg8, various stress-response proteins, proteins containing the WSC domain and the DUF3129 domain (domain of unknown function). The DUF3129 is found in the gas1 protein of the Magnaporthe grisea that participate in appressorial penetration and lesion formation during infection of rice (Quest et al., 2013). It was interesting to observed that DUF3129 was highly expressed in $M$. cionopagum whereas this domain was not expressed at all in A. dactyloides. DUF3129 was identified in twelve transcripts among the Top500 most expressed transcripts in the library of $M$. cionopagum infecting $H$. schachtii. During $A$. oligospora infections, this domain was identified in one transcript in $A$. oligospora infecting $M$. hapla and in four transcripts in A. oligospora infecting $H$. schachtii among the Top500 most expressed transcripts (Andersson et al., 2014). DUF3129 is an expanded gene family in nematode-trapping fungi and both $M$. haptotylum and $A$. oligospora have 33 genes encoding this domain (Meerupati et al., 2013). Seventeen of these genes were found among the $10 \%$ most expressed genes during nematode infection by $M$. haptotylum while only two were among the $10 \%$ most expressed genes during nematode infection by $A$. oligospora (Meerupati et al., 2013). Accordingly, the DUF3129 domain is highly expressed during infection among the species that form adhesive branches and adhesive knobs. Further studies are needed to investigate the function of the DUF3129 domain in the nematode-trapping fungi during infection. Transcripts encoding the fungal fruit-body lectin (FB_lectin) and the D-mannose binding lectin (B_lectin) were only highly expressed in A. oligospora (adhesive net forming fungus) but not in $A$. dactyloides (Constricting rings forming fungus) and $M$. cionopagum (Adhesive branch forming fungus).

\section{Virulence associated transcripts}

A BLAST search of the top 500 transcripts in each library of nematode trapping fungi infecting host nematode species was conducted in the pathogen-host interaction protein database (PHI-base). In total, 97 unique PHI-base genes were identified. Among the 97 identified $\mathrm{PHI}$-base genes, 15 were highly expressed by $A$. oligospora, $A$. dactyloides and $M$. cionopagum during infection of plant parasitic nematodes. Virulence associated proteins expressed by nematode-trapping fungi included antioxidant, calcium binding protein, cell signaling (Pkinase), cell signalling (Ras), DEAD-box RNA helicase, membrane transport (Cation transport ATPase (P-type) family, morphogenesis (Serine/threonine-protein phosphatase), non-specific DNA-binding proteins (HMG box), stress response (FKBP-type peptidyl-prolyl cistrans isomerase), stress response (Peptidylprolyl isomerase), transcription (Repressor Tup1), Woronin body major protein (Andersson, et al., 2014). The PHI-base genes that differ in expression between the nematode- trapping fungi included aspartic proteases and the gas 1 and gas 2 proteins of $M$. grisea (Xue et al., 2000) that contains the DUF3129 domain (domain of unknown function).

\section{Nematode host-specific gene expression}

Gene expression in A. oligospora during the infection of $M$. hapla versus $H$. schachtii showed that a majority of the genes had similar expression levels. 105 genes were at least 5-fold upregulated during trapping and infection of $M$. hapla compared to trapping and infection of $H$. schachtii and 65 genes were at least 5-fold upregulated in $A$. oligospora during infection of $H$. schachtii compared 
to $M$. hapla. Genes predicted to encode secreted proteins were enriched among the differentially expressed genes in both nematodes. The differentially expressed genes encoding proteins with a predicted secretion signal were further characterized. They included peptidases, glucosidases and several gene families that were expanded in the genomes of nematode-trapping fungi such as DUF3129, WSC and tyrosinase (Meerupati et al., 2013). Five of the in total 22 secreted differentially expressed genes were assigned as small secreted proteins (SSPs) with unknown function (Andersson et al., 2014).

\section{CONCLUSION}

The importance of nematode-trapping fungi arises from their potential use as biological control agent of plantand animal- parasitic nematodes. In order to understand the evolution of parasitism in nematode trapping fungi, genomics, and transcriptomics were studied. By sequencing the genome of an adhesive knob forming fungus $M$. haptotylum and by analyzing comparative transcriptomics to the adhesive trap forming fungus $A$. oligospora, the gene duplication followed by functional diversification has played a major role in the evolution of parasitic nature of nematode trapping fungi. The differential regulation of orthologous genus has been an important mechanism for the evolution of parasitism in the nematode-trapping fungi in response to the nematode host. Comparative transcriptome analysis showed that the divergence in gene expression between the species of nematode trapping fungi was significantly larger than that related to the plant-parasitic nematode host. A core set of transcripts being highly expressed by all three fungi during infection of plant parasitic nematodes included subtilisins, aspartic proteases and proteins containing the CFEM domain. These genes were also found highly expressed by $A$. oligospora and $M$. haptotylum during infection of $C$. briggsae. Also within this core set, a putative nematotoxic protein was identified, the Ricin-B lectin. A more variable set of transcripts in the fungal species was also identified. A small group of genes was identified showing differential expression depending on the plant parasitic nematode host. This group was enriched in genes encoding secreted proteins and also included several gene families that were expanded in the genomes of nematode-trapping fungi. Knowledge of the genomic interspecific variation in the trapping mechanisms and host preferences will be useful for researchers for identification of more potent nematodetrapping fungi for management of plant parasitic nematodes. A. dactyloides and $D$. brochopaga were observed to form conidial traps and kill the nematodes in soil which indicates that conidia based formulations of these fungi could be used as potential product for application in root-knot infested soil for management of plant-parasitic nematodes.

\section{ACKNOWLEDGEMENTS}

The author is thankful to Department of Science and Technology, New Delhi, Government of India for providing the DST Boyscast Fellowship to work on gene expression in nematode trapping fungi under the guidance of Prof. Anders Tunlid and Dr. Dag Ahrén at Section of Microbial Ecology, Department of Biology, Ecology Building, Lund University, Sweden. Author is also thankful to Swedish Research Council for financial support of some part of this work.

\section{REFERENCES}

Andersson KM, Meerupati T, Levander F, Friman E, Ahrén D and Tunlid A (2013). Proteome of the nematode-trapping cells of the fungus Monacrosporium haptotylum. Appl. Environ Microbiol. 79: 4993-5004.

Andersson KM, Kumar D, Bentzer J, Friman E, Ahrén D and Tunlid A (2014). Interspecific and host-related gene expression patterns in nematode-trapping fungi. $B M C$ Genomi. 15: 968.

Braun BR, Head WS, Wang MX and Johnson AD (2000). Identification and Characterization of TUP1-regulated genes in Candida albicans. Geneti. 156: 31-44.

Cox GN, Kusch M and Edgar RS (1981). Cuticle of Caenorhabditis elegans: its isolation and partial characterization. J. Cell Biol. 90: 7-17.

Dackman C and Nordbring-Hertz B (1992). Conidial traps - a new survival structure of the nematode-trapping fungus Arthrobotrys oligospora. Mycol. Res. 96: 194-198.

Dayhoff MO (1976). Origin and evolution of protein super families. Fed. Proc. 35: 2132-2138.

Dijksterhuis J, Veenhuis M, Harder W and Nordbring-Hertz B (1994) Nematophagous fungi: physiological aspects and structure-function relationships. Adv. Microb. Physiol. 36: 111-143.

Jansson HB, Tunlid A and Nordbring-Hertz B (1997). Biological control: Nematode. In: (Ed. Anke T) Fungal biotechnology. Chapman \& Hall, Weinheim, pp. 38-50.

Jansson HB and Lopez-Llorca LV (2001). Biology of nematophagous fungi. In: Mishra, JD and Horm, BW (Eds.). Trichomycetes and other fungal groups: Professor Robert W. Lichtwardt commemoration volume. Enfield, $\mathrm{NH}$ : Science Publisher. Inc. pp. 145-173.

Kulkarni RD, Kelkar HS and Dean RA (2003). An eight-cysteinecontaining CFEM domain unique to a group of fungal membrane proteins. Trends Biochem. Sci. 28: 118-121.

Kumar D, Singh KP and Jaiswal RK (2005). Screening of different media and substrates for cultural variability and mass culture of Arthrobotrys dactyloides Drechsler. Mycobiol. 32: 215-222.

Kumar D and Singh KP (2006). Assessment of predacity and efficacy test of Arthrobotrys dactyloides against root knot disease of tomato. J. Phypathol. 154: 1-5.

Kumar D, Maurya N, Kumar P, Singh H and Addy SK (2015). Assessment of germination and carnivorous activities of a nematode-trapping fungus Arthrobotrys dactyloides in fungistatic and fungicidal soil environment. Biol. Control 82: 76-85.

Lespinet O, Wolf YI, Koonin EV and Aravind L (2002). The role of lineage-specific gene family expansion in the evolution of eukaryotes. Genome Res. 12: 1048-1059.

Li D, Ashby AM and Johnstone K (2003). Molecular evidence that the extracellular cutinase Pbc1 is required for pathogenicity of Pyrenopeziza brassicae on oilseed rape. Mol. Plant Microbe Interact. 16: 545-552. 
Meerupati T, Andersson KM, Friman E, Kumar D, Tunlid A and Ahrén D (2013). Genomic mechanisms accounting for the adaptation to parasitism in nematode-trapping fungi. PLOS Genet. 9: e1003909.

Persmark L and Nordbring-Hertz B (1997). Conidial trap formation of nematode-trapping fungi in soil and soil extracts. FEMS-Microbiolo-Ecolog. 22: 313-323.

Quast C, Pruesse E, Yilmaz P, Gerken J, Schweer T, Yarza P, Peplies J and Glockner FO (2013). The SILVA ribosomal RNA gene database project: improved data processing and web-based tools. Nucleic Acids Res. 41: D590D596.

Rubner A (1996). Revision of predacious hyphomycetes in the Dactylella-Monacrosporium complex. Stud. in Mycol. 39: 1-134

Singh H (2010). Studies on Dactylaria brochopaga Drechsler with special reference to its bio-control potential against root-knot nemtodes, Meloidogyne incognita (Kofoid \& White) Chitwood on tomato. M.Sc. (Ag.) Plant Pathology (Nematology) thesis. N.D. University of Agriculture and Technology, Kumarganj, Faizabad, U.P., India.
Singh KP, Jaiswal RK, Kumar N and Kumar D (2007). Nematophagous fungi associated with root galls of rice caused by Meloidogyne graminicola and its control by Arhthrobotrys dactyloides and Dactylaria brochopaga. J. Phytopathol. 155: 193-197.

Veneault-Fourrey C, Lambou K and Lebrun MH (2006). Fungal Pls1 tetraspanins as key factors of penetration into host plants: a role in re-establishing polarized growth in the appressorium. FEMS Microbiol. Lett. 256: 179-184.

Winnenburg R, Baldwin TK, Urban M, Rawlings C, Köhler, J, et al. (2006). PHI-base: a new database for pathogen host interactions. Nucleic Acids Res. 34: D459-D464.

Xue C, Park G, Choi W and Zheng L (2002). Two novel fungal virulence genes specifically expressed in appressoria of the rice blast fungus. Pl. Cell 14: 2107-2119.

Yang J, Wang L, Ji X, Feng Y, Li X, et al. (2011). Genomic and proteomic analyses of the fungus Arthrobotrys oligospora provide insights into nematode-trap formation. PLoS Pathog. 7: e1002179.

Zopf W (1888). Zur. Kenntnis der Infections-Krankheiten niederer Tiere. Nova Acta Leop. Academy of Nature. Halle, 52: 7. 